\title{
FleXibilização CURRICUlaR: CONCEPÇões E PRÁticas À LUZ dAS PRODUÇÕES CIENTÍFICAS BRASILEIRAS
}

\author{
CURRICULAR FLEXIBILIZATION: CONCEPTIONS AND PRACTICES IN THE LIGHT OF \\ BRAZILIAN SCIENTIFIC PRODUCTIONS
}

FLEXIBILIDAD CURRICULAR: CONCEPCIONES Y PRÁCTICAS A LA LUZ DE LAS PRODUCCIONES CIENTÍFICAS BRASILEÑAS

\author{
Glauce Barros Santos \\ Sousa Araujo \\ (iD) 9 \\ Doutoranda em Ensino \\ (UNIVATES) \\ Professor na Faculdade de Floriano \\ (FAESF) \\ glauce.barros@bol.com.br
}

\section{Eniz Conceição Oliveira (iD) 9}

Pós-doutorado na Universidade de Aveiro (UA)

Docente da Universidade do Vale do Taquari-(UNIVATES)

Docente do Programa de PósGraduação em Ensino-(PPGE-

Ensino) e Programa de Pós-

Graduação em Ciências Exatas-

(PPGECE)

eniz@univates.br

\begin{abstract}
Resumo
Neste artigo se apresentam resultados do estado da arte que procurou analisar as produções científicas brasileiras sobre as concepções e práticas da Flexibilização Curricular. Discute-se sobre os resultados quantitativos e qualitativos de informações sobre a temática presentes no Catálogo de Teses e Dissertações e Portal de Periódicos da Capes, entre os anos de 2010 e 2020. Utilizou-se a análise textual discursiva (ATD), a partir da qual emergiram quatro categorias oriundas das interpretações da desfragmentação dos textos analisados: possibilidades na flexibilização dos currículos para uma aprendizagem significativa; metodologias ativas de ensino; práticas pedagógicas e suas contribuições na autonomia e potencialidades dos alunos; e atividades complementares. Os estudos evidenciaram que a flexibilização curricular deve ser construída por meio de conteúdos flexíveis, bem como por métodos ativos e práticas pedagógicas inovadoras e pelo desenvolvimento de atividades complementares. Dessa forma, tais relações podem promover aprendizagens autônomas, críticas, reflexivas e transformadoras nos alunos.
\end{abstract}

Palavras-chave: Flexibilização Curricular. Mudanças. Aprendizagens.

Recebido em: 8 de janeiro de 2021.

Aprovado em: 7 de fevereiro de 2021.

Como citar esse artigo (ABNT):

ARAUJO, Glauce Barros Santos Sousa; OLIVEIRA, Eniz Conceição. Flexibilização curricular: concepções e práticas à luz das produções científicas brasileiras. Revista Prática Docente, v. 6, n. $1, \mathrm{e} 004,2021$. 


\begin{abstract}
In this article it is presented results of the state of art that looked to analyze the Brazilian scientific productions about the conceptions and practices of curricular flexibilization. It is discussed about the quantitative and qualitative information about the theme present in the catalogue of thesis and dissertation and periodical portal of Capes, between the years 2010 and 2020. It was used the discursive textual analysis (DTA), from which emerged four categories coming from the interpretations of desfragmentation of the analyzed texts: possibilities in flexibilization of curriculums for a significant learning; active teaching methodologies; pedagogical practices and their contributions in autonomy and pontentialities of students; and complementary activities. The studies showed that curricular flexibilization must be done through flexible subjects, as well as by active methods and innovative pedagogical practices and by the development of additional activities. Thus, such relations can promote autonomous, critical, reflexive and transformative learnings in students.
\end{abstract}

Keywords: Curricular Flexibilization. Changes. Learnings.

\title{
Resumen
}

Este artículo presenta los resultados del estado del arte que buscó analizar las producciones científicas brasileñas sobre las concepciones y prácticas de la Flexibilidad Curricular, discutiendo los resultados cuantitativos y cualitativos de las informaciones sobre el tema presentes en el Catálogo de Tesis y Disertaciones y Portal Periódico de Capes, entre los años 2010 y 2020. Se utilizó el análisis textual discursivo (ATD), del que surgieron cuatro categorías a partir de las interpretaciones de la desfragmentación de los textos analizados: posibilidades em la flexibilidad de los currículos para un aprendizaje significativo; metodologías activas de enseñanza; prácticas pedagógicas y sus aportes a la autonomía y potencialidad de los estudiantes; y actividades complementarias. Los estudios han demostrado que la flexibilidad de los planes de estudio debe construirse mediante contenidos flexibles, así como métodos activos y prácticas pedagógicas innovadoras y el desarrollo de actividades complementarias. De este modo, dichas relaciones pueden promover un aprendizaje autónomo, crítico, reflexivo y transformador en los estudiantes.

Palabras clave: Flexibilidad de los Planes de Estúdio. Cambios. Aprendizaje. 


\section{INTRODUÇÃOO}

As mudanças educacionais estão cada vez mais vigentes em nosso meio, perpassando nos mais diversos contextos e situações. As discussões sempre estão presentes nas mais diversas falas e observações dos educadores e sociedade em relação aos conteúdos a serem ensinados, no que tange ao processo de ensino e aprendizagem, quanto às argumentações presentes nas competências e habilidades que os alunos devem desenvolver em sua vida pessoal e profissional, de forma plena e em sua totalidade, como, também, quais conteúdos a serem ensinados e de que forma esses possam ser aprendidos de modo desfragmentado e distante da realidade dos estudantes.

É importante destacar que o currículo não pode ser um elemento estático e padronizado, mas deve ser apontado como um caminho a ser seguido. Desse modo, as flexibilizações curriculares se inserem nesse contexto, como forma de entender o processo do currículo nas mais diversas formas e situações. Isso posto, este trabalho apresenta uma breve revisão de literatura de estudos realizados nos últimos anos, no intuito de analisar as produções científicas brasileiras sobre as concepções e práticas da Flexibilização Curricular.

Esta revisão de literatura é um segmento de uma pesquisa de doutorado que vem sendo desenvolvida no Programa de Pós-Graduação em Ensino na Universidade do Vale do Taquari/RS, que busca compreender a implementação da flexibilização curricular nas escolas de tempo integral na cidade de Floriano-Piauí. O presente estudo tem como problema de pesquisa: $\mathrm{O}$ que dizem as produções científicas brasileiras sobre as concepções e práticas da Flexibilização Curricular?

Como forma de estruturar este estudo, na primeira parte discorreremos sobre as percepções acerca da flexibilização curricular; em seguida, as abordagens presentes nas publicações sobre a temática, buscando compreender suas práticas e os mais diversos contextos onde as mesmas estão inseridas; logo depois, o traçado metodológico, resultados e discussões e considerações finais.

\section{PERCEPÇÕES ACERCA DA FLEXIBILIZAÇÃo CURRICULAR}

É de suma importância discutir sobre o currículo, pois o mesmo é um segmento salutar no espaço escolar, pois permite entender sobre o processo organizacional que permeia os componentes curriculares, em sua dinamicidade nos espaços e condução no tempo, bem como todos os elementos organizacionais que envolvem a consolidação dos conteúdos de forma efetiva na escola. Mill (2014) cogita que efetivar a flexibilidade nos ambientes educacionais 
pressupõe levar em conta o tempo, os momentos de convívio entre alunos e professores, conteúdos, observar a logística e movimentações no espaço escolar.

Sacristán (2000) relata que o currículo não é algo inerte, estático e paralisado, mas um elemento complexo de aprendizagens, que devem contemplar experiências, saberes e vivências, e que os componentes curriculares necessitam atender às reais necessidades dos indivíduos, contribuindo, assim, em seu desenvolvimento pleno e em sua totalidade.

Senn (2013) enfatiza que a educação voltada para os princípios da diversidade e diferenças individuais dos sujeitos proporciona a flexibilização e a melhoria dos currículos, pois permite a participação dos alunos de forma ativa, contribuindo com o desenvolvimento de todos, sejam eles nos aspectos pessoais, sociais e/ou profissionais. Desse modo, as Diretrizes Curriculares Nacionais da Educação Básica (BRASIL, 2013) informam que os sistemas educacionais devem organizar os currículos de forma flexível e com inúmeras possibilidades, a fim de atender aos reais interesses dos alunos, como também seus desejos e necessidades.

Forgrad (2005) relata que a flexibilização curricular sempre deve estar pautada no respeito às diversidades dos sujeitos e nas práticas que se estabelecem no espaço escolar, observando o tempo, espaço e a organização educacional presente na escola, para que, assim, o processo de quebra de um modelo rígido e sistematizado atenda às reais necessidades e interesses dos alunos, em uma relação harmônica e equilibrada. Moran (2017) enfatiza que os modelos educacionais devem ser inovadores, pois, dessa forma, possibilita currículos flexíveis, oportunizando que os alunos possam escolher seus percursos de aprendizagens de acordo com suas expectativas e anseios, vinculados a conteúdos teóricos e práticos.

Diante disso, a flexibilização curricular se insere no contexto escolar como sendo um elemento importante na dinamicidade dos currículos, possibilitando que os componentes curriculares ensinados na escola sejam mais próximos dos estudantes, colaborando no desenvolvimento dos mesmos de forma ativa, possibilitando um ensino atraente e interessante para todos.

Forgrad (2005) aborda a importância da flexibilização dos currículos na apropriação das mais diversas formas de aprendizagens, levando em conta sempre a realidade onde os sujeitos estão inseridos. Também enfatiza que esse modelo de flexibilidade curricular proporciona o rompimento de um ensino puramente disciplinar e sistematizado, com a busca de uma articulação entre os saberes teóricos e práticos, em uma relação de integração entre elas. Cabral Neto (2004), colaborando nas percepções acerca da flexibilização curricular, comenta que: 
A flexibilização curricular substitui o modelo de grade por uma nova estrutura que possibilita ao aluno participar do processo de formação profissional; rompe com o enfoque unicamente disciplinar e sequenciado a partir de uma hierarquização artificial de conteúdos; cria novos espaços de aprendizagem; busca a articulação teoria e prática como princípio integrador (conectar o pensar ao fazer); possibilita ao aluno ampliar os horizontes do conhecimento e a aquisição de uma visão crítica que lhe permita extrapolar a aptidão específica de seu campo de atuação profissional e propicia a diversidade de experiências aos alunos (CABRAL NETO, 2004, p. 15).

Assim, a flexibilização curricular permite que os currículos sejam contextualizados e flexíveis, podendo integrar teoria e prática, possibilitando que o aluno possa ampliar seu conhecimento, sendo sujeito crítico e reflexivo no ambiente onde o mesmo está inserido, rompendo com uma aprendizagem rígida e sistematizada, dando margens a novas amplitudes de diversidades e vivências.

Carvalho e Picoli (2017) comentam que em resposta a uma configuração de um currículo padronizado e sistematizado, há uma proposta de um modelo de currículo flexível, que possa atender às reais necessidades dos estudantes, levando em conta a realidade onde todos estão inseridos, bem como as diversidades culturais e sociais, propiciando, assim, o fortalecimento da individualidade e subjetividade do sujeito, fomentando um currículo organizado de forma flexível e interdisciplinar.

A flexibilidade curricular só poderá acontecer quando os processos educacionais e suas práticas de ensino e aprendizagem forem diferenciadas, proporcionando aos estudantes aquisições de conhecimentos de forma integrada, como, também, possibilitando que os mesmos sejam sujeitos participativos, responsáveis e autônomos na sociedade, sendo construtores de seu projeto de vida (FERREIRA,2020).

Em vista disso, a flexibilização curricular possibilita que os estudantes possam se apropriar dos mais diversos saberes e conhecimentos de maneira contextualizada e flexível, rompendo com padrões sistematizados e rígidos, proporcionando a autonomia e a participação de todos no processo educacional, contribuindo com aprendizagens mais ativas e próximas da realidade dos mesmos.

\section{Metodologia}

O caminho metodológico traçado para a presente revisão de literatura recorreu como fonte de dados ao Catálogo de Teses e Dissertações da Capes, bem como o Portal de Periódicos da Capes. Ferreira (2002) relata que o estudo da arte consiste em aprofundar uma determinada área de um conhecimento, mapeando e discutindo os saberes, tentando compreender os resultados da investigação, os temas e campos ainda a serem investigados. 
Utilizou-se nas buscas o termo "flexibilização curricular", observando o mesmo no título, resumo e palavras-chaves. Salienta-se, também, como forma de lapidar a busca, que se aplicaram apenas trabalhos revisados por pares, na língua portuguesa, no período de 2010 a 2020.

Assim, finalizado o processo de busca, houve a dedicação às análises iniciais de forma quantitativa e, depois, às análises das publicações de forma qualitativa. Zanella (2013) comenta que o método quantitativo busca fazer quantificações de forma numérica, de maneira objetiva, quantificando os resultados obtidos. Já os métodos qualitativos se empenham em entender a realidade do fenômeno estudado, sem a utilização de dados numéricos, mas de forma interpretativa.

Enfatiza-se, também, que para a análise dos dados foi utilizada a análise textual discursiva (ATD), a fim de compreender os elementos vinculados à temática pesquisada de forma qualitativa, no qual permite manifestar novas interpretações e revelações a partir das leituras dos textos investigados (MORAES; GALIAZZI, 2011).

Diante disso, buscou-se analisar os textos seguindo os passos da análise textual discursiva (ATD) proposta por Moraes e Galiazzi (2011). O primeiro processo executado se referiu à unitarização, que permitiu a fragmentação dos resultados da pesquisa em pequenas unidades de significado a fim de obter as subcategorias de análises. Diante do procedimento executado na análise das leituras dos textos, foram denominadas quatro unidades de significados, a partir das quais surgiram as subcategorias. Desse modo, finalizou-se o primeiro passo da análise discursiva textual, intitulada como "unitarização".

O segundo processo executado se tratou da categorização que aconteceu a partir dos elementos encontrados na unitarização, buscando uma relação de sentidos, elementos comparativos e semelhanças entre as unidades de significados e as subcategorias. O terceiro processo consistiu no metatexto que oportunizou novas configurações e interpretações, estabelecendo a construção de perspectivas, apreciações e significações de sentido.

Diante disso, têm-se quatro categorias emergentes, a saber: 1) possibilidades na flexibilização dos currículos para uma aprendizagem significativa; 2) metodologias ativas de ensino: mudanças necessárias para o aperfeiçoamento do ensino e aprendizagem; 3) práticas pedagógicas e sua contribuição na autonomia e potencialidades dos alunos; 4) atividades complementares: auxiliando na formação e promoção dos estudantes. 
Mediante todas as buscas de publicações realizadas e analisadas, bem como efetivada o processo da ATD, trilha-se com a exposição dos resultados das análises quantitativas e análises qualitativas desta pesquisa.

\section{Resultados E Discussão}

\subsection{Corpus da Análise TeXtual Discursiva}

Diante das buscas realizadas no Catálogo de Teses e Dissertações da Capes, no período compreendido entre 2010 a 2020, e utilizando-se as buscas com o termo "flexibilização curricular", foram encontrados 46 trabalhos, e atendendo aos critérios de inclusão e exclusão, na observação do título, resumo e palavras-chaves, foram avaliadas 20 publicações, dentre elas 5 teses e 15 dissertações. Para a busca nos periódicos da Capes, seguindo o termo “flexibilização curricular", obteve-se 35 trabalhos revisados entre pares, sendo analisadas 5 publicações, levando em consideração os mesmos critérios de exclusão e inclusão realizados anteriormente.

Para melhor compreensão das análises realizadas de forma quantitativa, segue o Quadro 1, discriminando as publicações analisadas, a partir das quais emergiram as unidades de significado.

Quadro 1 - Estudos que emergiram as unidades de significados para a pesquisa

\begin{tabular}{|c|c|c|c|c|}
\hline Fonte & Título & Categoria & Ano & Autores \\
\hline \multirow{8}{*}{ 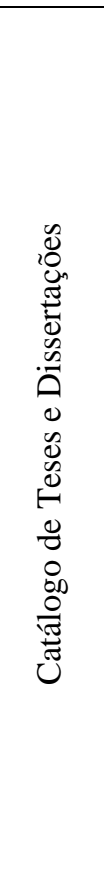 } & $\begin{array}{l}\text { Programa ensino médio inovador: um estudo sobre a } \\
\text { política de flexibilização curricular. }\end{array}$ & \multirow{8}{*}{ 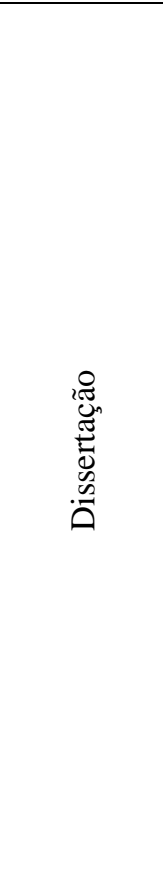 } & 2016 & Elaine Sinhorini Arneiro Picoli \\
\hline & $\begin{array}{l}\text { A flexibilização curricular no ensino médio integrado } \\
\text { a educação profissional. }\end{array}$ & & 2015 & $\begin{array}{l}\text { Rogileni Aparecida Bonomo } \\
\text { Crispim }\end{array}$ \\
\hline & $\begin{array}{l}\text { Reforma Universitária e flexibilização curricular: } \\
\text { uma análise do Reuni no Agreste alagoano. }\end{array}$ & & 2016 & Lavoisier Almeida dos Santos \\
\hline & $\begin{array}{l}\text { Flexibilização curricular: a proposta do ensino médio } \\
\text { inovador e a profissionalização do ensinar. }\end{array}$ & & 2016 & Marcelo Barbosa Pinto \\
\hline & $\begin{array}{c}\text { Diretrizes Curriculares Nacionais e a construção de } \\
\text { propostas curriculares inovadoras: um estudo de } \\
\text { cotejamento dos projetos políticos pedagógicos da } \\
\text { UNIRIO e UFMG. }\end{array}$ & & 2015 & Dayane da Silva Prudencio \\
\hline & $\begin{array}{l}\text { Inovação Organizacional: a adoção de um sistema de } \\
\text { gestão acadêmica por uma instituição de ensino } \\
\text { superior pública de Belo Horizonte. }\end{array}$ & & 2015 & Maria Betania Aparecida Campos \\
\hline & $\begin{array}{l}\text { O curso de pedagogia em uma instituição de ensino } \\
\text { público de São Luís: a formação multicultural em } \\
\text { foco. }\end{array}$ & & 2013 & Raul Germano de Sousa Vilhena \\
\hline & $\begin{array}{c}\text { Motivações e experiências de alunos em projeto de } \\
\text { extensão universitária em Hospital Pediátrico: o } \\
\text { projeto "alunos contadores de histórias do } \\
\text { IPPMG/UFRJ". }\end{array}$ & & 2013 & Sonia Steinhauser Motta \\
\hline
\end{tabular}


10.23926/RPD.2021.v6.n1.004.id982

\begin{tabular}{|c|c|c|c|c|}
\hline & $\begin{array}{l}\text { A implementação do Reuni na Universidade Federal } \\
\text { do Ceará no contexto da contrarreforma da educação } \\
\text { superior. }\end{array}$ & & 2017 & Agercicleiton Coelho Guerra \\
\hline & $\begin{array}{l}\text { Os labirintos da política de educação inclusiva: entre } \\
\text { o preconceito e o direito à educação. }\end{array}$ & & 2014 & Fernanda Gomes Serafim \\
\hline & $\begin{array}{c}\text { Políticas de ensino superior, graduação em terapia } \\
\text { ocupacional e o ensino de terapia ocupacional social } \\
\text { no Brasil. }\end{array}$ & & 2014 & Livia Celegati Pan \\
\hline & $\begin{array}{l}\text { A expansão da educação superior na UFMA (2010- } \\
\text { 2014) no contexto do Reuni. }\end{array}$ & & 2016 & Evandicleia Ferreira de Carvalho \\
\hline & $\begin{array}{l}\text { Flexibilizações curriculares e o aluno com deficiência } \\
\text { intelectual nos anos iniciais do ensino fundamental: } \\
\text { um caso de consultoria colaborativa no município de } \\
\text { Itatiaia/RJ. }\end{array}$ & & 2017 & $\begin{array}{l}\text { Caroline Vieira de Campos } \\
\text { Gonzalez dos Santos }\end{array}$ \\
\hline & $\begin{array}{l}\text { O processo de Bolonha e a universidade brasileira: } \\
\text { Aproximações a partir da análise de documentos } \\
\text { referenciais. }\end{array}$ & & 2013 & Ralf Hermes Siebiger \\
\hline & $\begin{array}{l}\text { Metodologias ativas de ensino e aprendizagem: a } \\
\text { percepção de professores do curso de nutrição de } \\
\text { uma Instituição de Ensino Superior na Amazônia } \\
\text { ocidental. }\end{array}$ & & 2017 & Rejane Fernandes Nogueira \\
\hline & $\begin{array}{c}\text { Paradoxos entre políticas de currículo e avaliação: } \\
\text { uma análise da relação entre os instrumentos de } \\
\text { avaliação externa e as diretrizes curriculares dos } \\
\text { cursos de graduação. }\end{array}$ & & 2016 & Blaise keniel da Cruz Duarte \\
\hline & $\begin{array}{c}\text { Planejamento e práticas curriculares nos processos de } \\
\text { alfabetização de alunos com deficiência intelectual: } \\
\text { experiências e trajetórias em tempos de educação } \\
\text { inclusiva. }\end{array}$ & $\ddot{8}$ & 2016 & Gessica Fabiely Fonseca \\
\hline & $\begin{array}{l}\text { Grupos de apoio entre professores e a inclusão: uma } \\
\text { reflexão sobre a reinvenção das práticas de docência } \\
\text { a partir da ênfase no ensino colaborativo. }\end{array}$ & & 2017 & Ana Carolina Lopes Venancio \\
\hline & $\begin{array}{l}\text { Efeitos de um programa colaborativo nas práticas } \\
\text { pedagógicas de professoras de alunos com autismo. }\end{array}$ & & 2016 & $\begin{array}{c}\text { Francisca Maria Gomes Cabral } \\
\text { Soares }\end{array}$ \\
\hline & $\begin{array}{l}\text { A importância das atividades complementares na } \\
\text { formação do aluno da graduação. }\end{array}$ & & 2015 & Mariangela Abrão \\
\hline & $\begin{array}{l}\text { Reuni e flexibilização curricular: o caso do curso de } \\
\text { Pedagogia da UFAL-Campus Arapiraca. }\end{array}$ & & 2018 & Lavoisier Almeida Santos \\
\hline & $\begin{array}{l}\text { Um novo olhar para altas habilidades/supertodatação } \\
\text { no município de São José dos Pinhais-PR. }\end{array}$ & & 2018 & $\begin{array}{c}\text { Domingas Fatima Cardoso Amaral } \\
\text { Thalita Maria Freire Maia Cordeiro } \\
\text { Elisangela André da Silva Costa }\end{array}$ \\
\hline 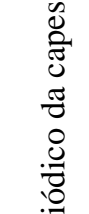 & $\begin{array}{c}\text { Revisitar processos: revisão da matriz curricular do } \\
\text { curso de Terapia Ocupacional da Universidade } \\
\text { Federal de São Paulo. }\end{array}$ & $\stackrel{8}{.00}$ & 2017 & $\begin{array}{c}\text { Andrea Perosa Saigh Jurdi } \\
\text { Stella Maris Nicolau } \\
\text { Lúcia da Rocha Uchôa Figueiredo } \\
\text { Rosana Aparecida Salvador Rossit } \\
\text { Viviane Santalucia Maximino }\end{array}$ \\
\hline 2 & $\begin{array}{l}\text { Educação em enfermagem: avaliação da formação } \\
\text { por egressos, empregadores e docentes. }\end{array}$ & & 2015 & $\begin{array}{c}\text { Maria Dyrce Dias Meira; Paulina } \\
\text { Kurcgant }\end{array}$ \\
\hline & $\begin{array}{l}\text { Psicologia organizacional e do trabalho: relato de } \\
\text { experiência em estágio supervisionado. }\end{array}$ & & 2015 & $\begin{array}{c}\text { Priscilla de Oliveira Martins Silva } \\
\text { Annor da Silva Junior } \\
\text { Mayra Barcelos Amado de Oliveira } \\
\text { Libardi } \\
\end{array}$ \\
\hline
\end{tabular}

Fonte: Banco de dados da Autora (2020).

Enfatiza-se que dentre essas publicações analisadas surgiram as unidades de significados, emergindo na efetivação da ATD, possibilitando novas visões de interpretações e 
percepções diante das leituras, revelando as categorias emergentes: possibilidades na flexibilização dos currículos para uma aprendizagem significativa; metodologias ativas de ensino: mudanças necessárias para o aperfeiçoamento do ensino e aprendizagem; práticas pedagógicas e sua contribuição na autonomia e potencialidades dos alunos; atividades complementares: auxiliando na formação e promoção dos estudantes. Salienta-se, também, que as mesmas despontaram diversos conhecimentos nas análises realizadas de forma qualitativa.

\subsection{As CATEgorias EMERgentes}

Moraes e Galiazzi (2011) comentam que a análise textual discursiva não segue um percurso único, tendo ponto de início e fim, mas permite que o pesquisador tenha um olhar diferente diante das leituras do texto, e que desponte expressões e percepções diferenciadas, dando, assim, novas formas de ver e sentir o texto, de maneira criativa e individualizada, fazendo com que cada um se permita a brincar com o texto, dando margens a novas interpretações e construção a partir das leituras do texto. Desse modo, os metatextos, sendo a parte final do processo da análise textual discursiva, permitiram que os dados fossem analisados de forma qualitativa, apontando como elementos importantes nas apreciações e observações do texto.

\subsubsection{Possibillidades da Flexibilização dos CURRÍculos PARA UMA APRENDIZAGEM SIGNIFICATIVA}

Muitos estudos têm abordado sobre o que deve ou não estar presente no currículo, bem como esses devem ser desenvolvidos na escola, levando em conta uma padronização única para todas as instituições ou possibilitar que os alunos possam participar efetivamente do processo organizacional do currículo, de acordo com seus desejos e aspirações. Nesse sentido, a flexibilização curricular se insere nesse contexto como forma de possibilitar a ruptura desse engessamento do currículo, dando vez e voz às novas possibilidades de conhecimentos e construção de saberes, de forma atrativa e motivacional, mais próximo dos estudantes.

Moreira e Silva (2002) relatam que o currículo corresponde aos elementos sociais, individuais e de interesses, firmando a identidade dos sujeitos, produzindo histórias em um determinado tempo, tanto na sociedade como na escola, devendo, assim, o currículo romper com a sistematização existente e possibilitar novos arranjos curriculares.

Desse modo, o currículo não pode ser considerado como algo estático e sistematizado, deve atender às peculiaridades da sociedade e dos sujeitos, possibilitando que os mesmos 
participem do processo organizacional, para o desenvolvimento de suas aprendizagens, dando margens as suas motivações, necessidades e interesses.

Percebe-se que o currículo envolve vários aspectos que vão desde a sua organização até a sua aplicação. A respeito de como os currículos devem atender aos alunos de forma plena, Pinto (2016) comenta:

Os currículos das escolas devem atender à diversidade de interesses, anseios, expectativas, condições e projetos de vida dos jovens estudantes. Não lhes impondo unicamente uma anacrônica grade de componentes com conteúdos fixos obrigatórios e padronizados. Ele deve proporcionar maior flexibilidade para a contextualização das realidades, superando o enciclopedismo (PINTO, 2016, p. 50).

Observa-se que o currículo deve proporcionar a todos os alunos conhecimentos que dialoguem com os seus desejos, necessidades e interesses, de forma flexível e contextualizada, rompendo com paradigmas e conteúdos definidos e sistematizados, como também precisa responder às perspectivas, às diferenças e às propensões dos mesmos, não sendo executada de forma imposta e separada das mais diversas situações.

Cabral Neto (2004) enfatiza que a flexibilização curricular possibilita a substituição de um currículo padronizado por um modelo que permite a participação dos alunos em sua formação e desenvolvimento, criando, assim, novos espaços de aprendizagens, ampliando a percepção crítica e reflexiva, bem como promovendo experiências e visões diferentes aos estudantes.

Abrão (2015) ressalta que a flexibilização curricular contribui para que os alunos possam adquirir conhecimentos de forma diferenciada e individualizada, pois a flexibilização remete a ideia de autonomia e independência, para que os mesmos possam construir os mais diversos saberes ao longo de sua trajetória, tornando-se, assim, sujeitos críticos, reflexivos e autônomos.

Para a efetivação de uma flexibilização curricular é necessário compreender que o currículo tem proposições definidas e deve atender às peculiaridades e singularidades existentes, a fim de obter o resultado esperado. Timoteo (2004) comenta que para acontecer à flexibilização curricular é preciso ter uma constante avaliação no projeto político pedagógico, no que diz respeito às suas diretrizes, às diversidades e diferenças existentes, experiências dos indivíduos, como também a valorização dos mais diversos saberes e conhecimentos em uma aprendizagem de forma colaborativa e interativa, fomentando a criticidade, a reflexão, o espírito investigativo e as trocas de experiências entre todos os envolvidos no processo educacional. 
Diante disso, a flexibilização curricular envolve elementos diversos como a participação de professores, alunos e uma organização no processo educacional, não de forma isolada e separada, mas levando em conta os mais diversos contextos e situações. Considera a integração de saberes e conhecimentos, fomentando, assim, aprendizagens integradas, colaborativas e mais próximas dos alunos, como também estimulando a criticidade, a reflexibilidade e o espírito investigativo entre todos os envolvidos no ambiente educacional.

Kuenzer (2017) comenta que a flexibilização curricular inserida na organização da reforma do ensino médio presente na Lei de n. ${ }^{\circ}$ 13.415/17, estabelece aprendizagens flexíveis, concedidas a partir de métodos inovadores, a diversidade e a interação, tendo, dessa forma, a necessidade de sua ampliação no ensino, a fim de atender às reais necessidades e demandas da sociedade, cada vez mais acirrada e competitiva.

A mesma autora relata que a flexibilização das aprendizagens permite a aquisição de conhecimentos baseada na interação, na pesquisa, na valorização do sujeito e das relações. Preocupa-se com o desenvolvimento crítico e reflexivo dos alunos, de forma colaborativa e não apenas como sendo receptores de conteúdos, mas peça fundamental desse processo de construção.

De acordo com Soares (2016), a flexibilização curricular traz subentendida os mais diversos valores, conhecimentos e atitudes dos professores em sua efetivação, pois é necessário sempre rever os instrumentos utilizados, os conteúdos a serem ensinados, bem como na aplicação de currículos atrativos e produtivos para uma melhor aprendizagem dos estudantes.

Na construção do currículo não se pode descartar os conhecimentos que os alunos já têm consigo, e, numa interação entre novos saberes, deve-se oportunizar que os sujeitos efetivem a aprendizagem significativa. Assim como relata Moreira (2012), a aprendizagem significativa acontece na interação entre os mais diversos conhecimentos e os saberes prévios dos estudantes, que são estabelecidos numa relação de diálogo entre si, dando novos significados aos sujeitos de forma transformadora ou revelados pelos mesmos, dando margens a novas descobertas e significados aos próprios sujeitos.

Rogers (2001) aborda que a aprendizagem significativa deve ser provocativa, aquela que leva o sujeito a uma transformação nas suas escolhas, aptidões, interesses e singularidades, como também deve ser profunda e intensa em todos os sentidos. Isto posto, observa-se que a flexibilização curricular contribui nas aprendizagens, no respeito às diferenças, nos espaços de cooperação, na interação e nos diálogos, como também no fomento da criticidade dos sujeitos, dando sentido aos mesmos, atendendo as suas especificidades e individualidades e que, diante 
dessas abordagens, manifesta-se de forma positiva na aprendizagem significativa dos estudantes.

\subsubsection{Metodologias ativas de ENSINO: MUdANÇAS NECESSÁRias PARA O APERFEIÇOAMENTO DO ENSINO E APRENDIZAGEM}

Ao longo dos anos, muito se tem discutido sobre as mudanças necessárias no que tange à melhoria da educação. Discussões essas que percorrem todos os elementos que envolvem o processo educacional, em que os debates atualmente têm se centrado nos métodos ativos de aprendizagens, acreditando que esses contribuem para a autonomia e criticidade dos sujeitos, favorecendo, assim, uma melhor aprendizagem para os mesmos, bem como no desenvolvimento pleno dos estudantes. Kim (2018) relata que as metodologias ativas são métodos de ensino que integram relações entre alunos, professores e conhecimentos, proporcionando um ensino por meio da investigação, da motivação, na imaginação e na busca de soluções para os problemas de forma prática e real.

A educação vivencia momentos de transformações, precisando que o processo educacional acompanhe as mudanças, como também atenda às reais necessidades dos sujeitos. Diante disso, Moran (2017) comenta que:

\footnotetext{
Num mundo em profunda transformação a educação precisa ser muito mais flexível, híbrida, digital, ativa, diversificada. Os processos de aprendizagem são múltiplos, contínuos, híbridos, formais e informais, organizados e abertos, intencionais e não intencionais. Hoje há inúmeros caminhos de aprendizagem pessoais e grupais que concorrem e interagem simultânea e profundamente com os formais e que questionam a rigidez dos planejamentos pedagógicos das instituições educacionais (MORAN, 2017, p. 1).
}

Percebe-se que os processos de aprendizagens percorrem por vários caminhos, com suas particularidades, de maneira ativa, flexível e permanente, como também de forma híbrida, diversificados, multifacetados, desenvolvidos em seus aspectos formais e informais de aprendizagens, oportunizando as interações e as relações simultâneas, quebrando a rigidez dos planejamentos pedagógicos da escola.

Moran (2017) aborda que as aprendizagens ativas contribuem para a autonomia dos estudantes, pois essa aprendizagem tem foco no aluno como protagonista, na participação e na reflexão. Destaca, também, a respeito da flexibilidade que as aprendizagens de forma híbrida propiciam a todos, levando em conta o tempo, os espaços e os métodos que estão associados aos meios ativos. 
De acordo com Bordenave e Pereira (2015), o docente deve planejar suas ações e conteúdos a serem ministrados. Estes devem ser elaborados e desenvolvidos de maneira flexível, a fim de que o professor perceba as relações estabelecidas junto aos alunos, suas necessidades, interesses, percepções e motivações dos mesmos, contribuindo, assim, para a melhoria da aprendizagem de todos. Nogueira (2017) afirma que os professores que adotam as metodologias ativas em suas práticas docentes contribuem para o pensamento crítico dos estudantes, bem como na autonomia e construção dos saberes, em conformidade com as inferências que as sustentam.

Paiva et al. (2016) relatam que as metodologias ativas são métodos de ensino que desfazem o modelo tradicional de ensino, utilizando-se de métodos problematizadores, fomentando no aluno a autonomia, o espírito de descoberta e investigação, como também a aprendizagem significativa.

Sendo assim, a metodologia ativa propicia aos alunos a criticidade, a reflexividade, a criatividade e o espírito investigativo, tornando, dessa forma, uma aprendizagem interativa, dinâmica e inovadora, fazendo com que os sujeitos se apropriem dos mais diversos conhecimentos de forma flexível, numa relação de diálogos e comunicações uns com os outros, tornando a aprendizagem mais significativa para todos e mais próxima da realidade dos mesmos, dos seus interesses, motivações e necessidades.

\subsubsection{Práticas Pedagógicas E Sua contribuição na autonomia E POTENCIALIDADES DOS ALUNOS}

As constantes transformações educacionais repercutem diretamente nas práticas pedagógicas no ambiente escolar, pois os professores devem acompanhar as mudanças que estão acontecendo em seu meio, a fim de desenvolverem suas práticas docentes, atendendo às reais necessidades dos alunos, seus interesses e motivações para aprender.

O docente não pode ser visto apenas como um sujeito transmissor de conhecimentos, mas um elemento de mediação entre o ensino e o conhecimento, estimulando as mais diversas aprendizagens dos alunos de forma ativa e autônoma, fomentando a criatividade, a busca do saber, a curiosidade e a descoberta.

Bordenave e Pereira (2015) relatam que o professor deve saber sobre o seu importante papel na obtenção dos conhecimentos, pois precisa estar seguro e confiante na execução de suas práticas, para que, assim, possa contribuir de forma positiva nas aprendizagens dos alunos de forma 
plena e significativa colaborando na formação e no desenvolvimento dos estudantes nos aspectos sociais, afetivos, nas relações de interação e comunicação entre todos.

Segundo Tardif (2012), os conhecimentos dos docentes não são adquiridos de uma vez só, mas apropriados ao longo de sua trajetória profissional, e que aos poucos os mesmos se sentem mais seguros em suas atividades, internalizando suas práticas e ações, em um processo de construção cotidiana de ação e reflexão de suas práticas docentes.

Nesse sentido, os professores assumem responsabilidades no que tange ao desenvolvimento de suas práticas docentes, para que, dessa forma, os mesmos possam repassar os conhecimentos e saberes aos alunos de maneira segura, reflexiva e crítica, efetivando em suas práticas pedagógicas elementos importantes para as aprendizagens dos estudantes.

Franco (2015) aborda que as aprendizagens dos estudantes acontecem nas variadas formas de ensinar e que essas potencializam no ambiente escolar, fazendo com que os conhecimentos e saberes sejam significativos para os mesmos, bem como estimulantes, motivadores e que despertem a vontade de aprender. O professor deve ser formado para ser um sujeito crítico e comunicativo, conhecendo os elementos que envolvem a sua prática docente, para que possa enfrentar os desafios existentes em suas atividades cotidianas.

Para Sacristán (2000), as práticas pedagógicas estão intimamente vinculadas com o currículo, haja vista que esse se manifesta como uma construção cultural desenvolvida juntamente com as práticas pedagógicas, nos mais diversos contextos e situações, integrando o ensino e as práticas docentes no processo de construção, de maneira crítica e reflexiva no ato de ensinar. Tardif (2012) aborda que o professor não é mero transmissor de conhecimentos, pois a sua prática docente integra os mais variados conhecimentos, que são adquiridos através de sua formação e dos currículos, bem como de sua prática diária.

Isso posto, as práticas pedagógicas assumem papel importante no ambiente escolar, contribuindo para a melhor aprendizagem dos estudantes, pois as práticas docentes envolvem elementos diversos, que se integram e se relacionam nos diferentes contextos e situações, não sendo apenas elementos de reprodução de saberes, mas integrando currículos, a sua formação e práticas sendo alinhadas e articuladas com conhecimentos diversos, colaborando na construção do pensamento e no ato de ensinar cotidianamente de forma crítica e reflexiva.

\subsubsection{ATIVIDADES COMPLEMENTARES: AUXILIANDO NA FORMAÇÃO E PROMOÇÃO DOS ESTUDANTES}

As atividades complementares possibilitam um melhor desenvolvimento e formação dos estudantes, bem como no fomento de muitos elementos como afirma Abrão (2015). As 
atividades complementares assumem elementos inovadores, possibilitando uma complementação na formação e desenvolvimento dos estudantes, bem como na integração dos currículos, fomentando, assim, a quebra dos currículos sistematizados e padronizados, como forma de ampliar os conhecimentos e saberes dos estudantes e na formação e integração no ensino, na pesquisa e na extensão.

A mesma autora comenta que as atividades complementares possibilitam aos estudantes a aquisição dos conhecimentos, saberes e experiências, apropriação de temáticas diversas de diferentes formas, contextos e situações, favorecendo uma melhor formação e desenvolvimento pessoal e profissional, de forma ética, crítica, reflexiva e responsável.

A Base Nacional Comum Curricular (MINISTÉRIO DA EDUCAÇÃO, 2019) enfatiza sobre o contexto de uma educação de forma integral que promova as mais diversas aprendizagens.

\begin{abstract}
Independentemente da duração da jornada escolar, o conceito de educação integral com o qual a BNCC está comprometida se refere à construção intencional de processos educativos que promovam aprendizagens sintonizadas com as necessidades, as possibilidades e os interesses dos estudantes e, também, com os desafios da sociedade contemporânea. Isso supõe considerar as diferentes infâncias e juventudes, as diversas culturas juvenis e seu potencial de criar novas formas de existir. Assim, a BNCC propõe a superação da fragmentação radicalmente disciplinar do conhecimento, o estímulo à sua aplicação na vida real, à importância do contexto para dar sentido ao que se aprende e o protagonismo do estudante em sua aprendizagem e na construção de seu projeto de vida (MINISTÉRIO DA EDUCAÇÃO, 2019, p. 14-15).
\end{abstract}

Diante disso, para que aconteça na prática uma educação integral é de suma importância que as aprendizagens dos estudantes sejam realizadas de acordo com suas necessidades, interesses e mais próxima da realidade dos mesmos, bem como deve superar as fragmentações disciplinares, fomentando a autonomia e o protagonismo dos alunos, desenvolvendo e construindo significados em seu projeto de vida.

Desse modo, acredita-se que as atividades complementares desenvolvidas nas escolas vêm a contribuir para a formação e o desenvolvimento dos estudantes de forma integral e em sua totalidade, devendo estar em consonância com o projeto pedagógico da escola e ser parte integrante do currículo, para que, assim, não haja um contexto fragmentado, mas ampliação de conhecimentos e saberes de forma integrada, participativa e coletiva entre todos os envolvidos no ambiente educacional.

Pileggi et al. (2005) enfatizam que as atividades complementares vêm a cada dia se tornando importantes no que tange ao desenvolvimento e formação dos estudantes, pois os 
mesmos se apropriam de diversos conhecimentos, promovendo as mais diversas competências que não são contempladas nas disciplinas curriculares.

O artigo 17 do inciso 13, da resolução de n. ${ }^{\circ}$ 3, de 21 de novembro de 2018 (BRASIL, 2018), aborda sobre a forma e organização dos currículos, enfatizando que os alunos devem desenvolver diferentes atividades consideradas parte da carga horária, como: cursos, oficinas, atividades de extensão, pesquisas de campo e iniciação científica, atividades pedagógicas orientandas pelos professores de forma presencial ou a distância.

Diante disso, percebe-se a importância das atividades complementares realizadas no ambiente escolar como forma de promover o desenvolvimento dos estudantes de maneira autônoma, crítica e reflexiva, bem como proporcionando diferentes aprendizagens de forma participativa e integrada com os demais espaços e tempos destinados à melhor formação dos alunos.

Face as análises das produções científicas brasileiras, observou-se que a flexibilização curricular surge como um elemento importante no currículo, como forma de proporcionar aos estudantes conteúdos mais flexíveis e próximos da realidade dos mesmos, dando novas possibilidades de aprendizagens daquelas ofertadas com conteúdos rígidos e padronizados e sem significação para os alunos. É importante ressaltar também que as metodologias ativas contribuem na ruptura de um ensino padronizado e que estas proporcionam aos estudantes aprendizagens autônomas, críticas, motivadoras e reflexivas, pois os alunos adquirem conhecimentos de forma flexível e estimuladora, tornando a aprendizagem significativa e mais próxima dos mesmos.

Ressalta-se também que as práticas pedagógicas inovadoras são importantes para a efetivação da flexibilização curricular, pois o docente não pode ser um mero disseminador de conteúdos, mas um moderador do conhecimento, contribuindo na melhor formação e desenvolvimento dos estudantes de forma plena e em sua totalidade.

Diante das leituras aponta-se que as atividades complementares contribuem na melhor integração dos currículos, rompendo também com a padronização e rigidez curricular, proporcionado aos estudantes a aquisição de saberes de forma diferenciada e diversificada, das mais diversas formas, contextos e situações.

Desse modo, os conhecimentos aqui apresentados contribuem na melhor compreensão acerca da flexibilização curricular, onde as práticas efetivas das mesmas, contribuem para uma 
melhor formação e desenvolvimento dos estudantes, como também possibilitando aos alunos aprendizagens autônomas, críticas e reflexivas dos mesmos.

\section{CONSIDERAÇÕES FINAIS}

A flexibilização curricular se encontra nas mais diversas abordagens, contextos e situações, perpassando pelos currículos de forma a torná-lo mais flexível, diminuindo a rigidez e a sistematização do mesmo. Essa flexibilização se depara na educação superior e, também, na educação básica, sendo desenvolvida como parte integrante do projeto político pedagógico da instituição, como forma de promover os mais diversos conhecimentos e aprendizagens aos estudantes, contribuindo, assim, no desenvolvimento e formação dos mesmos de forma integral e em sua totalidade, levando em conta os aspectos sociais, econômicos, afetivos, culturais e educacionais.

Os estudos evidenciaram que a flexibilização curricular deve ser construída por meio de conteúdos flexíveis, bem como por métodos ativos e práticas pedagógicas inovadoras e pelo desenvolvimento de atividades complementares. Dessa forma, tais relações podem promover aprendizagens autônomas, críticas, reflexivas e transformadoras nos alunos.

Neste estudo sobre a flexibilização curricular emergiram quatro categorias a partir da ATD, em que ficou evidente a importância da flexibilização curricular na ruptura de um currículo normatizado e sistematizado, possibilitando novas abordagens, situações e contextos de aprendizagens, na melhoria da promoção e formação dos alunos. Salienta-se, também, que é necessário um aprofundamento dos estudos sobre a flexibilização curricular, compreendendo, assim, a sua implementação e desenvolvimento nos mais diversos espaços de aprendizagens, bem como a sua efetivação junto aos alunos e professores na construção dos saberes e conhecimentos.

\section{REFERÊNCIAS}

ABRÃO, Mariangela. A importância das atividades complementares na formação do aluno da graduação. 2015. - 235 f. Campinas: Tese (Doutorado em Educação) Universidade Estadual de Campinas, Campinas, 2015. Disponível em:

https://cutt.ly/qgPGuTY. Acesso em: 29 set. 2020.

BORDENAVE, Juan Diaz; PEREIRA, Adair Martins. Estratégias de ensino-aprendizagem. 4. ed. Petrópolis: Vozes, 2015.

BRASIL. Ministério da Educação. Diretrizes Curriculares Nacionais Gerais da Educação Básica. Brasília: MEC, SEB, DICEI, 2013. Disponível em: https://cutt.ly/wgPGo0C. Acesso em: 13 set. 2020. 
BRASIL. Resolução no 3, de 21 de novembro de 2018. Atualiza as Diretrizes Curriculares Nacionais para o Ensino Médio. Diário Oficial [da] República Federativa do Brasil, Brasília, DF, 22 nov. 2018. Disponível em: https://cutt.ly/agSWNx6. Acesso em: 1 out. 2020.

CABRAL NETO, Antonio. Flexibilização curricular: cenários e desafios. Natal, RN: EDUFRN - Editora da UFRN, 2004. Disponível em: https://cutt.ly/hgPGL1y. Acesso em: 15 set. 2020.

CARVALHO, Elma Júlia Gonçalves de; PICOLI, Elaine Sinhorini Arneiro. Políticas de flexibilização Curricular: Uma análise sobre o programa ensino médio inovador (Proemi). Revista Educere et Educare, v. 12, n. 24, p. 1-20, 2017. Disponível em: http://erevista.unioeste.br/index.php/educereeteducare/article/view/16385. Acesso em: 14 set. 2020.

FERREIRA, Norma Sandra de Almeida. As pesquisas denominadas "estado da arte". Educação \& Sociedade, v. 23, n. 79, p. 257-272, 2002. Disponível em: https://doi.org/10.1590/S0101-73302002000300013. Acesso em: 28 set. 2020.

FERREIRA, Carlos Alberto. A flexibilidade curricular: um estìmulo à mudança das práticas pedagógicas. Revista Espaço do Currículo, v. 13, n. 2, p. 316-325, 2020. Disponível em: https://doi.org/10.22478/ufpb.1983-1579.2020v13n2.45563. Acesso em: 14 set. 2020.

FORGRAD. Anteprojeto de lei da educação superior: contribuições do Forgrad. Unesp, 2005. Disponível em: https://cutt.ly/rgPF0Bc. Acesso em: 14 set. 2020.

FRANCO, Maria Amélia Santoro. Práticas pedagógicas de ensinar-aprender: por entre resistências e resignações. Educação e Pesquisa, v. 41, n. 3, p. 601-614, 2015. Disponível em: https://doi.org/10.1590/S1517-9702201507140384. Acesso em: 22 set. 2020.

KIM, Leila. Métodos ativos de ensino: coconstrução subjetiva da capacidade de pensar o próprio pensamento em sala de aula. Revista Brasileira de Psicodrama, v. 26, n. 1, p. 3140, 2018. Disponível em: https://doi.org/10.15329/2318-0498.20180015. Acesso em: 20 set. 2020 .

KUENZER, Acacia Zeneida. Trabalho e escola: a flexibilização do ensino médio no contexto do regime de acumulação flexível. Educação \& Sociedade, v. 38, n. 139, p. 331-354, 2017. Disponível em: https://doi.org/10.1590/es0101-73302017177723. Acesso em: 19 set. 2020.

MILL, Daniel. Flexibilidade educacional na cibercultura: analisando espaços, tempos e currículo em produções científicas da área educacional. RIED. Revista Iberoamericana de Educación a Distancia, v. 17, n. 2, p. 97-126, 2014. Disponível em: https://doi.org/10.5944/ried.17.2.12680. Acesso em: 14 set. 2020.

MINISTÉRIO DA EDUCAÇÃO. Base Nacional Comum Curricular. MEC, 2019. Disponível em: http://basenacionalcomum.mec.gov.br/images/historico/BNCC_EnsinoMedio_embaixa_site_ 110518.pdf. Acesso em: 1 nov. 2020.

MORAES, Roque; GALIAZZI, Maria do Carmo. Análise Textual Discursiva. Ijuí: Editora Unijuí, 2011. 
MORAN, José. Metodologias ativas e modelos híbridos na educação. In: YAEGASHI, Solange Franci Raimundo et al. (org.). Novas Tecnologias Digitais: Reflexões sobre mediação, aprendizagem e desenvolvimento. Curitiba: CRV, 2017. p. 23-35. Disponível em: https://cutt.ly/agPGSlq. Acesso em: 13 set. 2020.

MOREIRA, Marco Antonio. ¿Al final, qué es aprendizaje significativo? Qurriculum, v. 25, p. 29-56, 2012. Disponível em: http://riull.ull.es/xmlui/handle/915/10652. Acesso em: 20 set. 2020 .

MOREIRA, Antonio Flávio Barbosa; SILVA, Tomaz Tadeu da. Currículo, cultura e sociedade. São Paulo: Cortez, 2002.

NOGUEIRA, Rejane Fernandes. Metodologias ativas de ensino e aprendizagem: a percepção de professores do Curso de Nutrição de uma Instituição de Ensino Superior na Amazônia Ocidental. 2017. - 166f. Dissertação (Mestrado Profissional em Ensino em Ciências da Saúde) - Programa de Pós-Graduação em Ensino em Ciências da Saúde (MPECS), Fundação Universidade Federal de Rondônia (UNIR), Porto Velho, 2017. Disponível em: https://www.ri.unir.br/jspui/handle/123456789/2575. Acesso em: 18 set. 2020.

PAIVA, Marlla Rúbya Ferreira et al. Metodologias ativas de ensino-aprendizagem: revisão integrativa. SANARE, v. 15, n. 02, p. 145-153, 2016. Disponível em: https://sanare.emnuvens.com.br/sanare/article/view/1049. Acesso em: 20 set. 2020.

PILEGGI, Gisele et al. Formação do engenheiro de produção: participação dos discentes em atividades complementares. In: , 2005, Campina Grande. XXXIII Congresso Brasileiro de Ensino de Enganharia. Campina Grande: ABENGE/UFCG-UFPE, 2005. p. 1-7. Disponível em: https://cutt.ly/FgSWBps. Acesso em: 30 set. 2020.

PINTO, Marcelo Barbosa. Flexibilização curricular: a proposta do ensino médio inovador e a profissionalização do ensinar. 2016. - 108 f. Foz do Iguaçu: Dissertação (Mestrado em Ciências, Linguagens, Tecnologias e Cultura) - Universidade Estadual do Oeste do Paraná, Foz do Iguaçu, 2016. Disponível em: http://tede.unioeste.br/handle/tede/1016. Acesso em: 18 set. 2020.

ROGERS, Carl Ransom. Tornar-se pessoa. 5. ed. São Paulo: Martins, 2001.

SACRISTÁN, José Gimeno. O currículo: uma reflexão sobre a prática. 3. ed. Porto Alegre: Artmed, 2000.

SENN, Kátia Elizabeth Drosda. Currículo Adaptado e Flexível: Desafios e Possibilidades. 2013. - 36 f. União da Vitória: Monografia (Pós-Graduação em Educação Especial) Secretaria de Estado da Educação do Paraná, Superintendência da Educação, Diretoria de Políticas e Programas Educacionais, Programa de Desenvolvimento Educacional, União da Vitória, 2013. Disponível em: https://cutt.ly/ogPGs2V. Acesso em: 13 set. 2020.

SOARES, Francisca Maria Gomes Cabral. Efeitos de um programa colaborativo nas práticas pedagógicas de professoras de alunos com autismo. 2016. - 220 f. Rio de Janeiro: Tese (Doutorado em Educação) - Universidade do Estado do Rio de Janeiro, Rio de Janeiro, 2016. Disponível em: https://cutt.ly/EgAxDPw. Acesso em: 18 set. 2020. 
TARDIF, Maurice. Saberes docentes e formação profissional. Petrópolis: Vozes, 2012.

TIMOTEO, Rosalba Pessoa de Souza. A Universidade e a flexibilização curricular: dilemas e desafios a enfrentar. Flexibilização curricular: cenários e desafios. Natal, RN: EDUFRN Editora da UFRN, 2004. p. 19-30. Disponível em: https://cutt.ly/hgAxuAJ. Acesso em: 15 set. 2020.

ZANELLA, Liane Carly Hermes. Metodologia de pesquisa. 2. ed. Florianópolis: UFSC, 2013. Disponível em: https://cutt.ly/IgPHDQ6. Acesso em: 15 set. 2020. 